\title{
Performance Investigation of a Vertical Wave-plate Mist Eliminator with Perforated Plates
}

\author{
Seung-Yoon Noh ${ }^{1}$, Moon-Won Kim², Se-Jin Yook ${ }^{1,2 *}$ \\ ${ }^{1}$ School of Mechanical Engineering, Hanyang University, Seoul, Korea \\ 2 Department of Convergence Defense, Hanyang University, Seoul, Korea
}

\begin{abstract}
This study improved collection efficiency of the mist eliminator used for wet flue gas desulfurization facilities. The commonly used wave-plate mist eliminator with a drainage channel was chosen as a reference model and its performance was compared with the performance of a wave-plate mist eliminator with perforated plates attached to the front of each drainage channel. Simulations were performed to compare the dust collection performance of the mist eliminators. We could confirm that the addition of perforated plates to the mist eliminator changed the particle behavior in front of the drainage channel and induced the passage of particles through the mist eliminator and into the drainage channel. Subsequent experiments confirmed that dust collection performance was improved with the use of the perforated plates. The use of the mist eliminator designed in this study is expected to greatly reduce the amount of air pollutants emitted from various industrial facilities.
\end{abstract}

Keywords: Aerosol; Mist eliminator; Inertial separator; Collection efficiency.

\section{INTRODUCTION}

Recently, as the number of days with high concentration of fine dust particles, defined as particulate matter (PM) that is less than $10 \mu \mathrm{m}$, in the air has increased, there has been greater interest in the study of fine dust. Studies worldwide have reported that fine dust may adversely affect human health. It has also been found that fine dust can cause lung cancer (Pope et al., 2002), and death due to respiratory diseases have been shown to be closely related to atmospheric $\mathrm{PM}_{2.5}$ concentrations (Guaita et al., 2011; Perez et al., 2012; Kim et al., 2018). In addition, exposure to fine dust can lead to a variety of diseases, including cardiovascular disease, bronchial asthma, atherosclerosis, premature death, and birth defects (Basu et al., 2014; Kang and Kim, 2014; Lung et al., 2016); therefore, it is essential to investigate ways to reduce the atmospheric concentration of fine dust. Atmospheric fine dust is emitted from various industrial and living environments. In particular, various studies show that particulate matter is generated during power generation processes that use fossil fuels, such as coal-fired power plants. Consequently, it was confirmed that a large amount of fine dust of $\mathrm{PM}_{10}$ and $\mathrm{PM}_{2.5}$ is released (Zhang et al., 2005; Goodarzi, 2006; Din et al.,

\footnotetext{
* Corresponding author.

Tel.: +82-2-2220-0422; Fax: +82-2-2220-2299

E-mail address: ysjnuri@ hanyang.ac.kr
}

2013; Manousakas et al., 2013; Lu et al., 2019). In order to reduce the emissions of fine dust and $\mathrm{SO}_{\mathrm{x}}$, a thermal power plant is generally equipped with a selective catalytic reduction system, an electrostatic precipitator, and a flue gas desulfurization (FGD) facility. A mist eliminator is installed in the FGD to remove droplets used for absorbing $\mathrm{SO}_{\mathrm{x}}(\mathrm{Kim}$ et al., 2019).

If the collection efficiency of the mist eliminator, which is involved in the collection of fine dust, can be improved, it can greatly contribute to the reduction of particulate matter emissions from thermal power plants. Therefore, various studies on mist eliminators have been conducted. An electrostatic mist eliminator, that has a low differential pressure and can improve the collection efficiency of fine dust, was developed by Kim et al. (2019), and the collection efficiency was compared based on the structure of the drainage channel of the mist eliminator. A study by James et al. (2003) showed that higher collection efficiencies were observed for the same flow rate, when drainage channels were included. The collection efficiencies of horizontal and vertical arrays of wire mesh, in mist eliminators, were compared in a study by Brunazzi and Paglianti (1998). The collection efficiencies, according to vane spacing and vane turning angle of the mist eliminator, were compared in a study by Narimani and Shahhoseini (2011), and collection efficiency was highest at a vane spacing of $20 \mathrm{~mm}$, flow rate of $5 \mathrm{~m} \mathrm{~s}^{-1}$, and vane angle of $60^{\circ}$. Three types of vertical mist eliminators, knitted wire mesh, crushed aluminum turnings, and multiple pass louvers, were compared under 
the same differential pressure or at the same flow rate by Bell and Strauss (1973). This study showed that under the same differential pressure, the collection efficiency was highest in the knitted wire mesh; and at the same flow rate, it was highest in the louver eliminator. Three different models of axial cyclone mist eliminators were designed and compared experimentally by Brunazzi et al. (2003). The collection efficiencies of five drift mist eliminators, bent into different models, were compared by Zamora and Kaiser (2011). Wave-plate mist eliminators with two different widths and channel numbers were compared by Galletti et al. (2008) through a simulation, and the collection efficiency was higher in large and wide models at the same inlet flow rate. The effects of the wire diameter and the packing density on the collection efficiency in the wire mesh eliminator were analyzed by Al-Daughaither et al. (2010), and the collection efficiency increased when wire diameter was decreased and the packing density increased. Recently, double pocket vane mist eliminator was developed and commercialized by many companies due to its large capacity and good separation efficiency (Chandranegara, 2016; Dries and Hoffmann, 2019).

Previous studies have focused on improving dust collection efficiency by changing the design model of existing mist eliminators. Because the mist eliminator with drainage channels has been proven to be efficient in increasing separation efficiency for small droplets (Chandranegara,
2016), this study aimed at improving the performance of the mist eliminator with drainage channels. Therefore, as shown in Fig. 1(a), the wave-plate mist eliminator model, which is one of the basic models of the mist eliminator, was set as a reference for the design of a new model. This reference mist eliminator model was also used in various previous studies (James et al., 2003; Galletti et al., 2008; Narimani and Shahhoseini, 2011; Zamora and Kaiser, 2011). The newly designed mist eliminator model in this study is shown in Fig. 1(b), in which an additional plate with rectangular perforation was installed in front of the drainage channel of the reference model. The dimensions of the reference and the new mist eliminator are shown in Table 1. The optimized model of the perforated plate used in this study was derived through the simulation method. Consequently, a mist eliminator was created to place the perforated plate structure in front of each drainage channel and the collection efficiency was measured and compared through experiments.

\section{NUMERICAL METHOD}

In order to analyze the characteristics of the flow, according to the inlet flow rates of the mist eliminator, and to predict the collection efficiency, according to the changes in the characteristics of the flow, a numerical analysis was performed using ANSYS FLUENT Release 17.0. Since the (a)

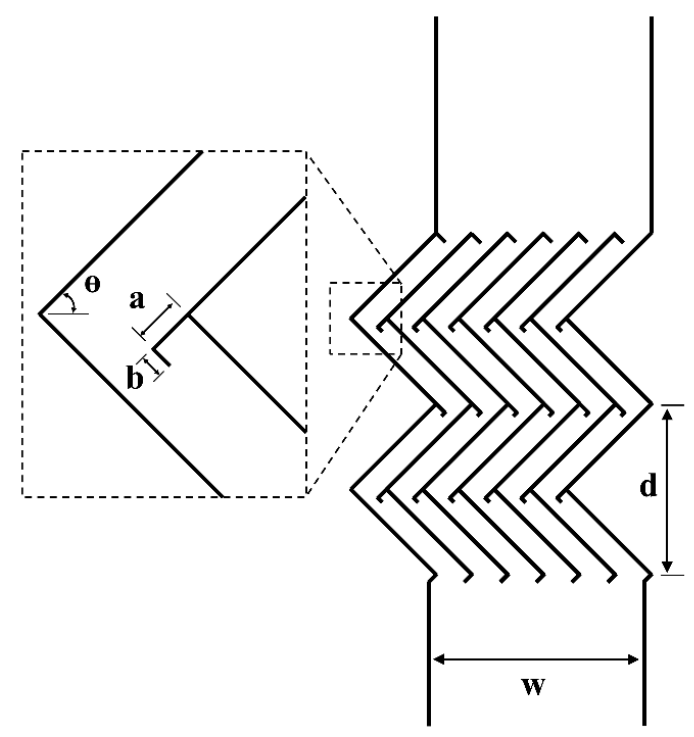

(b)

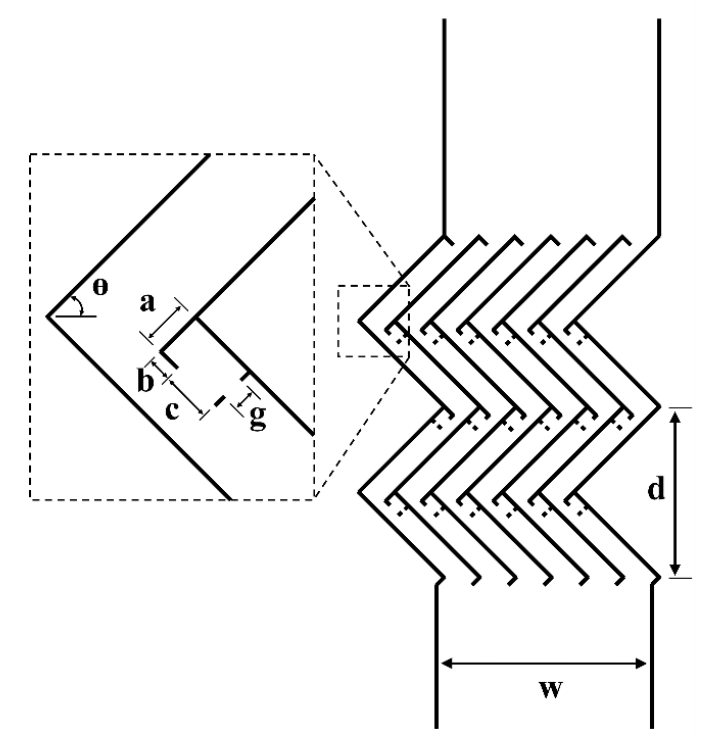

Fig. 1. Geometry of mist eliminator. (a) Reference mist eliminator, (b) Mist eliminator with perforated plates.

Table 1. Detailed dimensions of the mist eliminator.

\begin{tabular}{lll}
\hline Parameter & Reference Mist Eliminator & Mist Eliminator with Perforated Plates \\
\hline$\Theta$ & $45^{\circ}$ & $45^{\circ}$ \\
$\mathrm{a}$ & $8.6 \mathrm{~mm}$ & $8.6 \mathrm{~mm}$ \\
$\mathrm{~b}$ & $4.3 \mathrm{~mm}$ & $4.3 \mathrm{~mm}$ \\
$\mathrm{c}$ & - & $8.6 \mathrm{~mm}$ \\
$\mathrm{~d}$ & $118.5 \mathrm{~mm}$ & $118.5 \mathrm{~mm}$ \\
$\mathrm{~g}$ & - & $4.3 \mathrm{~mm}$ \\
$\mathrm{w}$ & $150 \mathrm{~mm}$ & $150 \mathrm{~mm}$ \\
\hline
\end{tabular}


mist eliminator model used in the actual wet flue gas desulfurization system has the same cross-sectional model that is repeated many times, two-dimensional (2D) analysis conditions were used to predict the performance of the mist eliminator. For reference, previous studies analyzing the dust collection efficiency of mist eliminators, using numerical analysis, have performed 2D analysis on only one of the six channels shown in Fig. 1(a) (James et al., 2003; James et al., 2005; Galletti et al., 2008). Flow was set to run from bottom to top. The flow in the mist eliminator is assumed to be steady, incompressible, and turbulent. The Reynolds Stress Method (RSM) model was used for turbulent flow analysis (Rafee et al., 2010; Estakhrsar and Rafee, 2013). The SIMPLE algorithm was used for pressure-velocity coupling.

The second-order upwind scheme was selected to solve the momentum equation, and to calculate the turbulent kinetic energy and turbulent dissipation rate. The boundary conditions for flow analysis at the flow inlet and outlet of the computational domain were, respectively, the velocity inlet and pressure outlet conditions, while the no-slip conditions were set at the wall of the absorption tower chamber and the surface of the mist eliminator. The flow rate of air flowing into the mist eliminator, through the inlet of the computational zone, was set to $2-5 \mathrm{~m} \mathrm{~s}^{-1}$, which is the flow rate of the commonly used wet flue gas desulfurization absorption tower (James et al., 2003; Kavousi et al., 2013). Structured grids were generated, and $\mathrm{y}+$ values were set to be lower than 1 (Galletti et al., 2008). As a result of the grid independence test, about 85,000 grids were selected. Based on the approaches of previous literature (Zamora and Kaiser, 2011; Estakhrsar and Rafee, 2013), the convergence criteria of the flow analysis were set so that all equations converged to $10^{-5}$ and all relative errors fell below $10^{-5}$ in the present study's simulations.

After the flow analysis was completed, particle behavior was analyzed using Discrete Phase Models (DPM), a particulate behavior analysis code embedded in FLUENT. For particulate behavior analysis, it was assumed that the particles were spherical and had a density of $1 \mathrm{~g} / \mathrm{cm}^{3}$. Stokes' drag force, operated by the relative flow of particles in the fluid, was taken into consideration, and the drag force was corrected using the slip correction factor according to the particle size (Kim et al., 2005). The number of particles released from the inlet of the mist eliminator channel was set to be 2500 . Due to the mist eliminator being modeled vertically, a downward gravitational force was taken into consideration. In order to account for the effects of the turbulent dispersion of particles, this study employed the discrete random walk (DRW) model, which calculates particle trajectories in a stochastic way by considering the fluctuations of turbulent flow velocity (ANSYS FLUENT User's Guide 15.0, 2013). In addition, it was assumed that all walls in the mist eliminator were applied with trap conditions and therefore it was assumed that the particles were trapped on the wall when they hit the wall.

\section{EXPERIMENTAL METHOD}

Fig. 2 shows a photograph of a mist eliminator with perforated plates as designed in this study. The mist eliminator

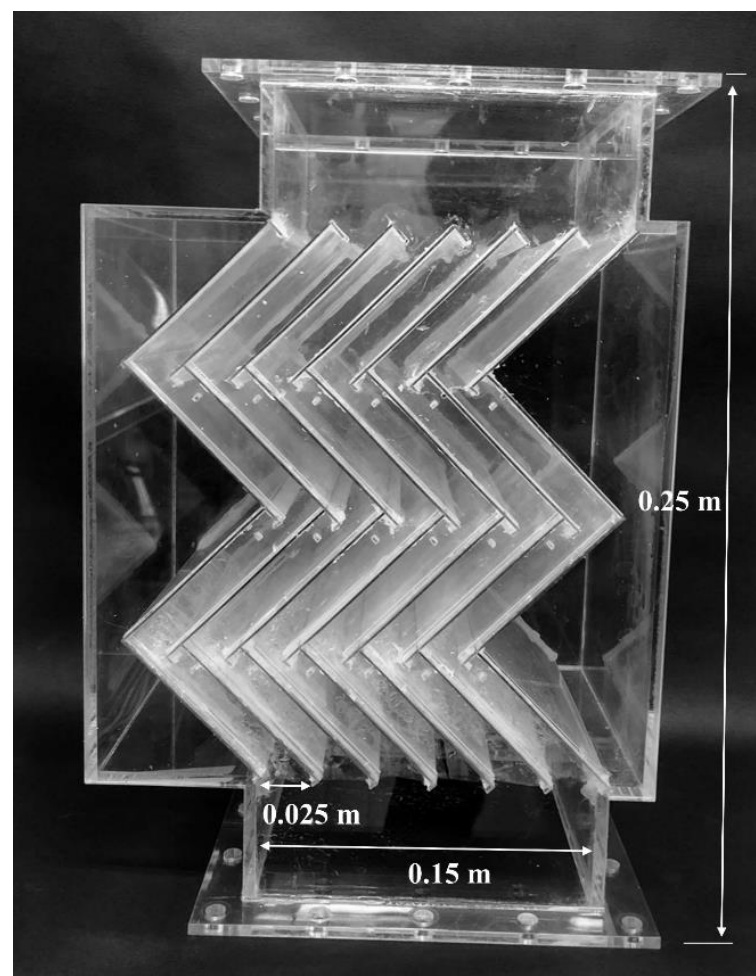

Fig. 2. Manufactured mist eliminator module.

was made of acrylic and consisted of six channels. The total height of the mist eliminator was $0.25 \mathrm{~m}$, the width of each channel was $0.025 \mathrm{~m}$, and the total width of the six channels was $0.15 \mathrm{~m}$. When no perforated plate was installed in front of the drainage channel, the model looked like Fig. 1(a) and when it was installed it looked like Fig. 1(b).

To verify the effect of removing particulate matter by the constructed mist eliminator, we used two types of experiment setups shown in Figs. 3 and 4. The height of the lab-scale chamber, which simulates the absorption tower of the wet flue gas desulfurization facility where the mist eliminator is installed, was $1.2 \mathrm{~m}$, and the gas flow rate inside the absorption tower was set to $2.5 \mathrm{~m} \mathrm{~s}^{-1}$. In a lab-scale chamber equipped with a mist eliminator, the flow was set to run vertically from bottom to top. Since the purpose of this study was to test the particle removal characteristics of the perforated plate equipped mist eliminator used in wet flue gas desulfurization, the chemical reaction to remove sulfur compounds was not considered. That is, instead of flue gas containing the sulfur compound, clean air that has passed through the High Efficiency Particulate Air (HEPA) filter was injected into the absorption tower.

The experiment setup to compare the collection efficiency is shown in Fig. 3, and instead of spraying limestone slurry to measure the collection efficiency of the mist eliminator, the Solid Aerosol Generator (SAG 410, TOPAS, Germany) was used to aerosolize Arizona Test Dust (ISO 12103-1, A4 type). The dust aerosol was injected into the absorption tower with clean air. Arizona Test Dust, before and after the flow containing particles passed through the mist eliminator, was sampled at an aerosolized state and was used to measure the number concentration distribution using an Optical 


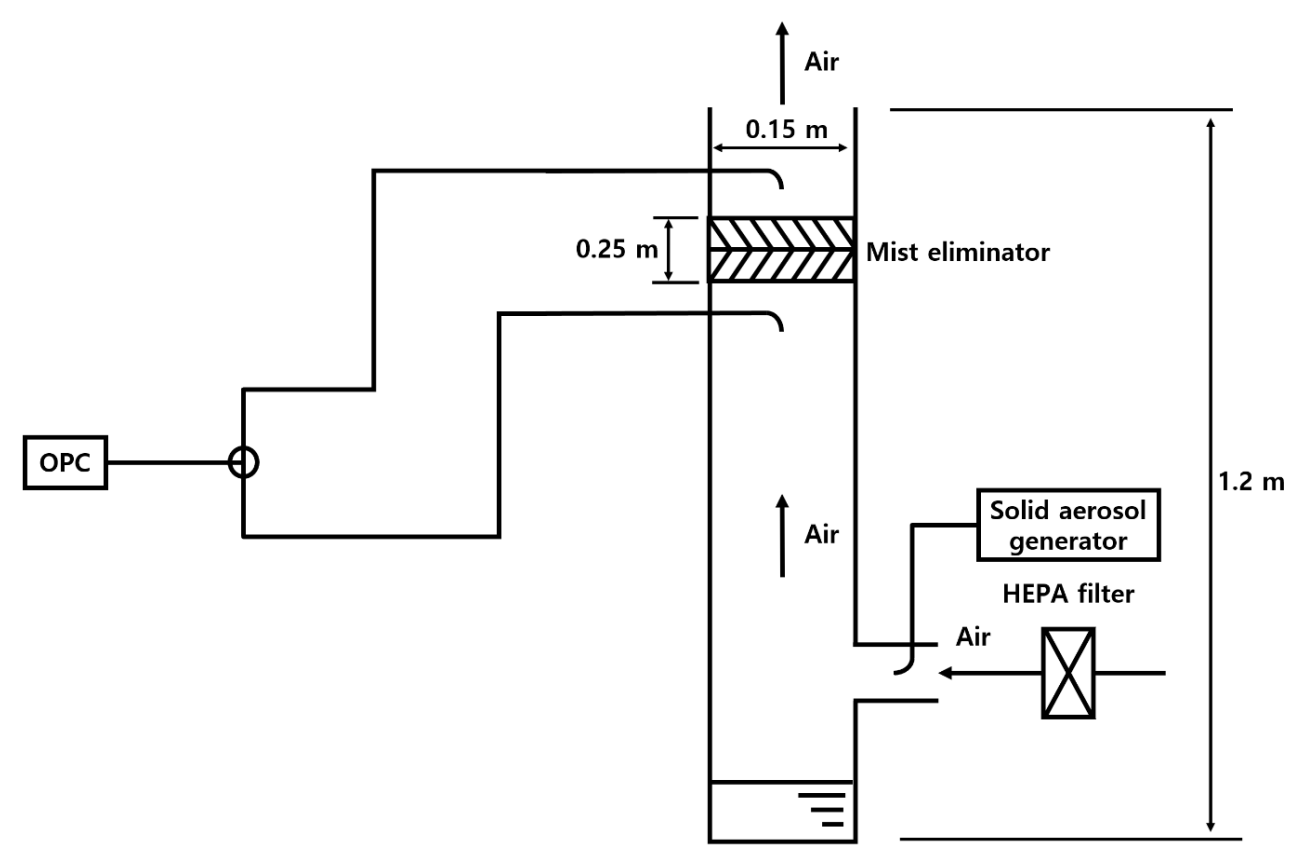

Fig. 3. Experimental setup for measuring collection efficiency.

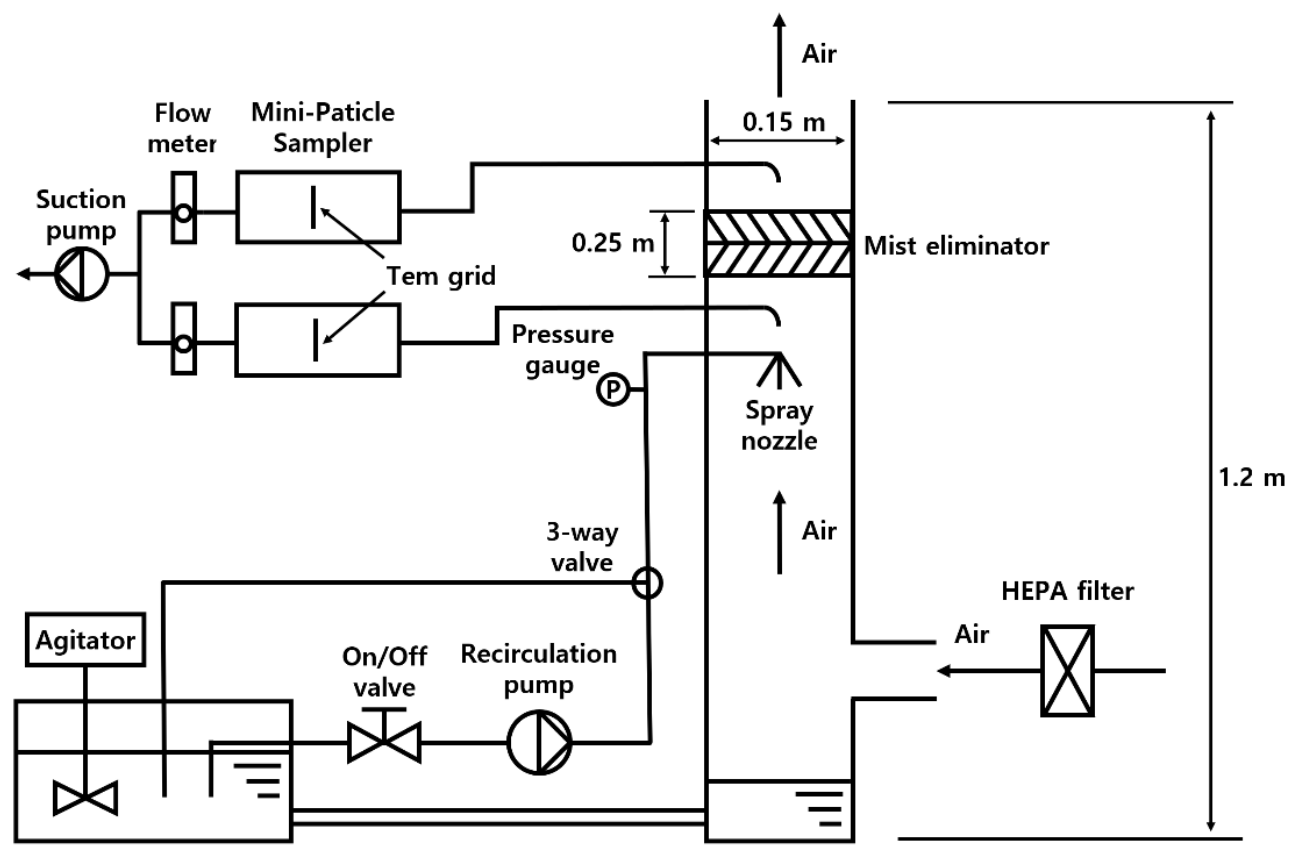

Limestone slurry tank

Fig. 4. Experimental setup for SEM analysis.

Particle Counter (OPC, Model 1.109, GRIMM, Germany). The following equation was used to determine the collection efficiency $(\eta)$ of the mist eliminator.

$$
\eta=1-\frac{C_{\text {after }}}{C_{\text {before }}}
$$

Here, $C_{\text {before }}$ and $C_{\text {after }}$ are, respectively, the aerosol number concentrations before and after the flow containing the particles passed through the mist eliminator. In addition, the density and dynamic shape factor of the Arizona Test Dust were set to $2.65 \mathrm{~g} \mathrm{~cm}^{-3}$ and 1.6 , respectively, and the particle size measured by OPC was converted into aerodynamic diameter using the following equation (Fletcher and Bright, 2000).

$d_{v e}=d_{a e} \sqrt{\frac{\rho_{0} C_{a e} \chi}{\rho_{p} C_{v e}}}$ 
Here, $\rho_{0}$ is $1 \mathrm{~g} \mathrm{~cm}^{-3}, \rho_{p}$ is $2.65 \mathrm{~g} \mathrm{~cm}^{-3}$ for the density of Arizona Test Dust, $C_{a e}$ and $C_{v e}$ are slip correction factors for aerodynamic diameter and volume equivalent diameter, and $\chi$ is 1.6, the dynamic shape factor for Arizona Test Dust (Peters et al., 2006).

Next, the limestone slurry was sprayed in the absorption tower chamber and experiment was performed to examine the efficiency with which the sprayed limestone slurry was removed by the mist eliminator. The experimental set-up for comparing the removal effect of limestone slurry in the actual reference mist eliminator model and the mist eliminator model with the perforated plate design of this study, are shown in Fig. 4. In order to generate the slurry particles used in the experiment, limestone powder (SSM-20, Seongshin Minefield, Korea) with an average particle size of $20 \mu \mathrm{m}$ was mixed with water in a ratio of $2: 3$ to create a slurry, and placed in a $100 \mathrm{~L}$ tank to prevent the precipitation of limestone powder and was stirred using an agitator (BL1003D, MTOPS, Korea). As shown in Fig. 4, limestone slurry was sprayed downwards using a full cone nozzle (KJ1/2FF-SS32, Kukje Nozzle, South Korea) into clean air filtered through a HEPA filter flowing from the bottom to top. At this time, the spray operation pressure was set to 3 bar. Sprayed limestone slurry particles were collected on a Transmission Electron Microscope (TEM) grid using a Mini Particle Sampler (MPS, Domaine Technologique, France) at locations before and after the flow containing the particles passed through the mist eliminator. Then, the morphology and amount of particles collected on the TEM grid were analyzed using a Scanning Electron Microscope (S4800, HITACHI, Japan).

\section{RESULTS AND DISCUSSION}

In order to confirm the accuracy of the predictions of the numerical analysis, experiments were conducted using Arizona Test Dust to quantitatively compare the collection efficiency. Fig. 5 is a graph comparing the collection efficiency according to aerodynamic diameter when the flow rate at the inlet of the mist eliminator is $2.5 \mathrm{~m} \mathrm{~s}^{-1}$ for both the reference model and the model including the perforated plate. As shown in Fig. 5, the simulation results were similar to the experimental results. The numerically predicted collection efficiencies were slightly higher than the experimental data for particle sizes in the range of about 5-12 $\mu \mathrm{m}$. This might be due to the fact that the simulation assumed the particles to be trapped on all walls including the side walls whereas in the experiment the particles which were not collected in the drainage channel could be re-suspended after they hit the side walls. The cut-off size of the reference model was about $5 \mu \mathrm{m}$, whereas the cut-off size of the mist eliminator model with the perforated plate design of this study was around 2 $\mu \mathrm{m}$. Therefore, the model with the perforated plate design of this study demonstrated a better dust collection performance than the reference model.

Fig. 6 is a graph comparing particle collection efficiency, according to flow rate, between the reference mist eliminator model and the model that includes the perforated plate design of this study. At all of the flow rates analyzed by simulation, $2 \mathrm{~m} \mathrm{~s}^{-1}, 3 \mathrm{~m} \mathrm{~s}^{-1}, 4 \mathrm{~m} \mathrm{~s}^{-1}$ and $5 \mathrm{~m} \mathrm{~s}^{-1}$, the collection efficiency of the perforated plate design was higher than that of the reference model. Especially at $2 \mathrm{~m} \mathrm{~s}^{-1}$, a cut-size reduction of about $2 \mu \mathrm{m}$ was observed. In other words, we could confirm that the dust collection efficiency was improved by installing the perforated plate. The reason why the collection efficiency was increased by installing a perforated plate in front of the drainage channel of the mist eliminator, can be explained through Fig. 7.

Fig. 7 is an image comparing particle behavior, near the third drainage channel of the reference mist eliminator model and the mist eliminator model with the perforated plate, through a simulation. In order to compare the two designs, the same number of particles were released at the same location in the inlet section of each mist eliminator. Because the mist eliminator with the perforated plate showed an

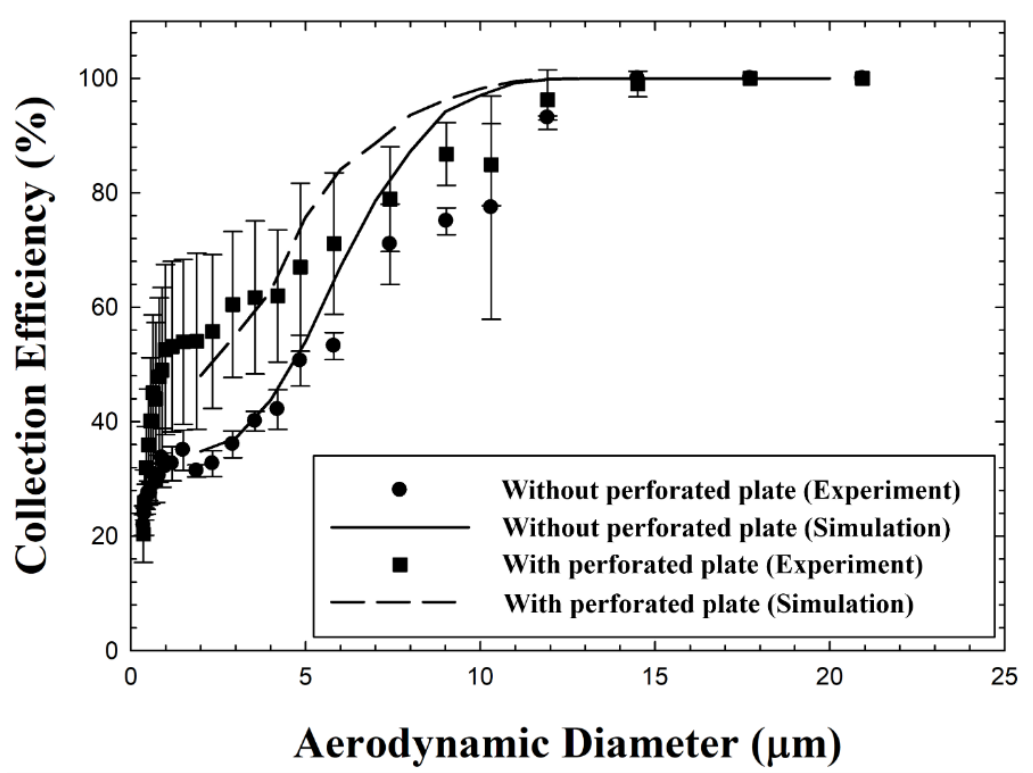

Fig. 5. Comparison of collection efficiency of each mist eliminator with $2.5 \mathrm{~m} \mathrm{~s}^{-1}$ inlet flow velocity. 


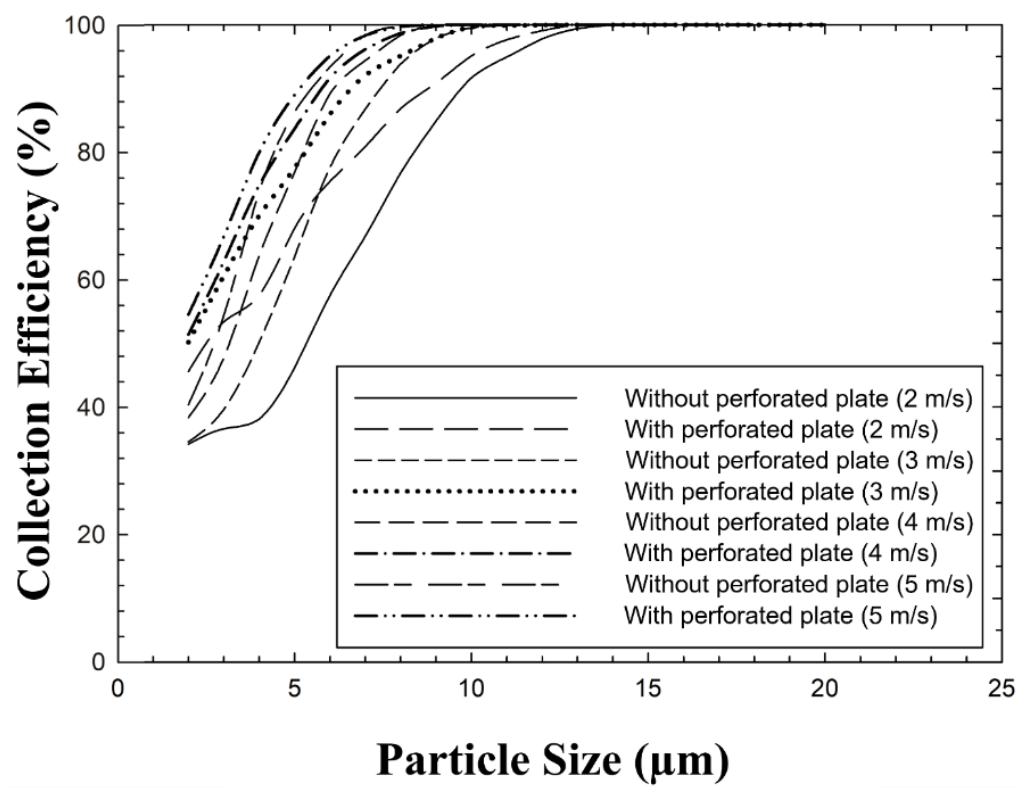

Fig. 6. Comparison of collection efficiency of each mist eliminator by inlet flow velocity.

(a)

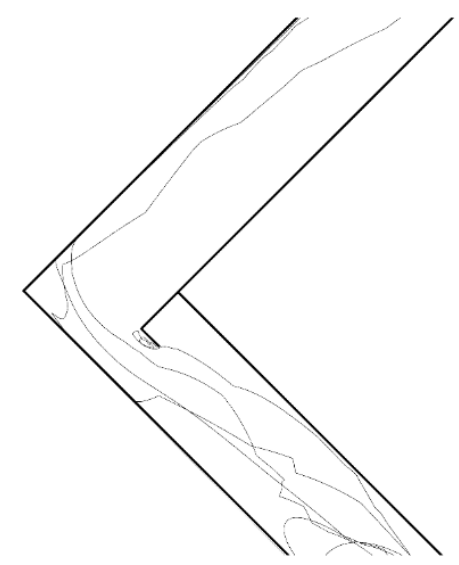

(b)

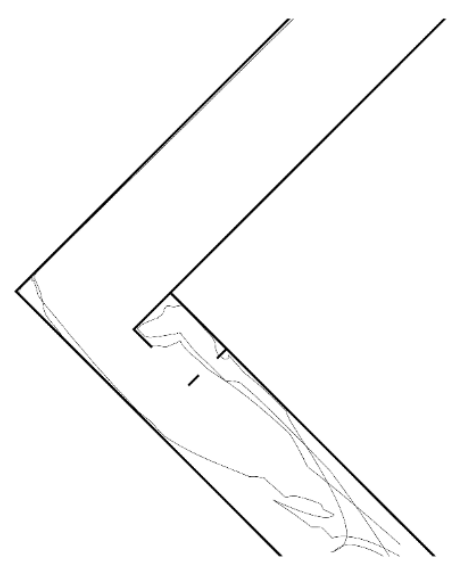

Fig. 7. Trajectories of $2-\mu \mathrm{m}$ particles near drainage channel in mist eliminator. (a) Reference mist eliminator, (b) Mist eliminator with perforated plate.

improved collection efficiency and its cut-off size was about $2 \mu \mathrm{m}$ as shown in Fig. 5, trajectories of $2-\mu \mathrm{m}$ particles were displayed in Fig. 7. Under the influence of the perforated plate installed mist eliminator, particles entering the drainage channel gathered in a perforated area, that is, in the center of the drainage channel, so that particles do not leave the drainage channel. Due to inertia, particles were collected in the drainage channel. On the other hand, in the reference model, the particles enter the outside of the drainage channel, which is an open area without any obstacles, and thus the particles are not collected in the drainage channel, and are easily released. Therefore, the installation of a perforated plate was found to play a significant role in the enhancement of particle collection efficiency of the mist eliminator.

On the other hand, experiments using limestone slurry particles were conducted to simulate the actual environment that the mist eliminator is operated in the thermal power plant.
An MPS with a TEM grid was used to sample particles before and after the mist eliminator for a qualitative comparison. Fig. 8 shows Scanning Electron Microscope (SEM) images of limestone slurry particles, sampled on the TEM grid, before and after the operation of each mist eliminator, for both the reference model and the model with the perforated plate. Figs. 8(a) and 8(c) are SEM images of limestone slurry particles sampled at the front of the two models of the mist eliminator. Both show similarities in particle size and number. In contrast, Figs. 8(b) and 8(d) show SEM images of limestone slurry particles sampled at the rear of the mist eliminator, for both the reference mist eliminator and the mist eliminator with the perforated plate, respectively. In the case of the mist eliminator with the perforated plate, both the size and number of sampled particles are smaller and lower than those of the reference model.

Fig. 9 shows the comparison of the number of particles 
(a)

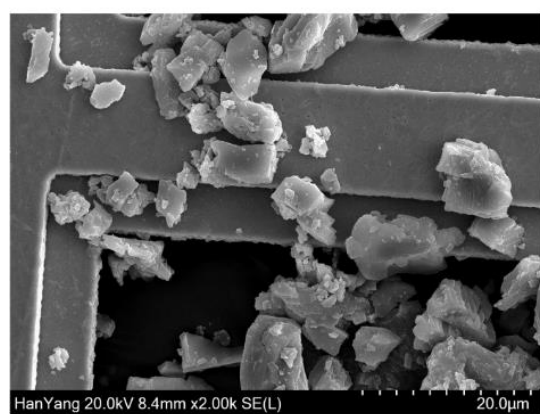

(c)

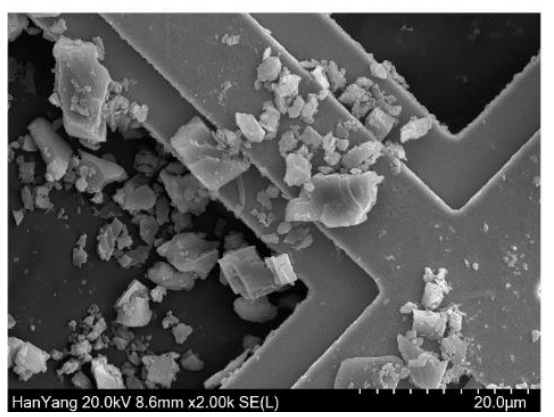

(b)

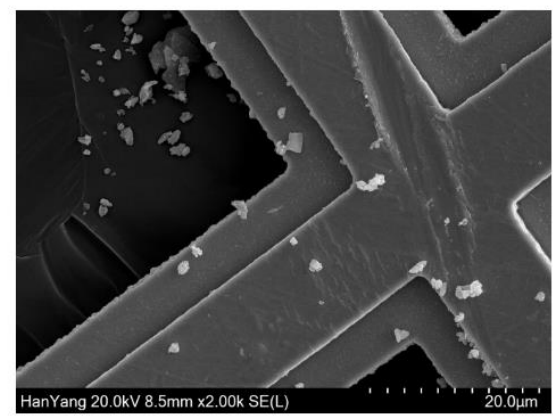

(d)

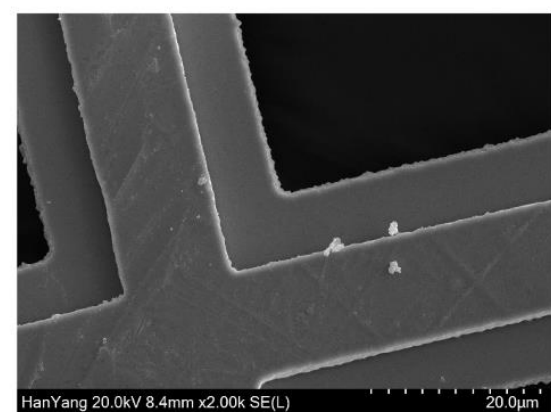

Fig. 8. SEM image (2000x magnification) of particles deposited on the TEM grid: (a) Upstream of reference mist eliminator case; (b) Downstream of reference mist eliminator case; (c) Upstream of mist eliminator with perforated plate case; (d) Downstream of mist eliminator with perforated plate case.

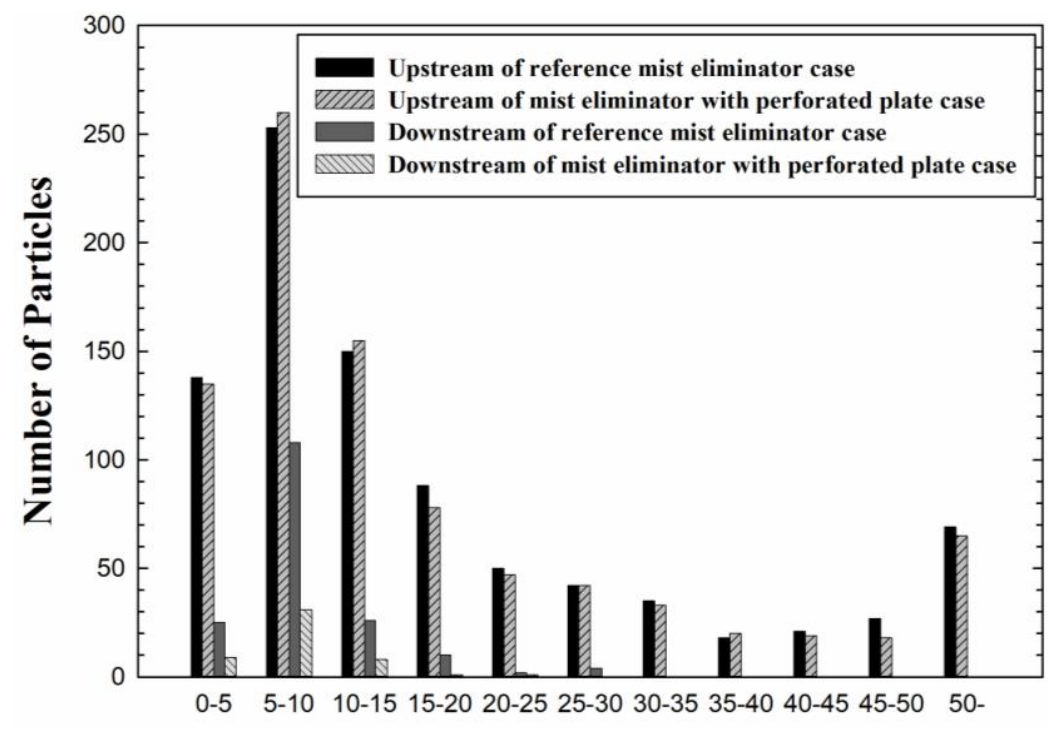

Particle Diameter $(\mu \mathrm{m})$

Fig. 9. Comparison of the number of particles deposited on the TEM grids installed upstream and downstream of the mist eliminators.

deposited on the TEM grids installed upstream and downstream of the mist eliminators with and without the perforated plate. For this quantitative comparison, several SEM images for each mist eliminator type were analyzed. The two mist eliminators showed very similar upstream conditions, however it is clearly seen that the number of particles sampled downstream of the mist eliminator with the perforated plate was much lower than that of the reference mist eliminator. These results are consistent with the results in Fig. 8, which means that the mist eliminator with the perforated plate designed in this study will be effective in the removal of particulate matter, even when applied to actual thermal power plants. 


\section{CONCLUSIONS}

In this study, we investigated a method for improving dust collection efficiency, by modifying the basic wave-plate mist eliminators installed in the wet flue gas desulfurization facility of thermal power plants, to remove particulate matter. Each bent area of the wave-plate mist eliminator was equipped with a drainage channel to collect particulate matter via inertia. Additionally, a perforated plate was installed at the front of each drainage channel to further enhance the inertial dust collection effect. First, a simulation was used to predict the dust collection efficiency of the mist eliminator with the perforated plate and the reference mist eliminator, at flow rates between $2-5 \mathrm{~m} \mathrm{~s}^{-1}$. The results showed that the collection efficiency, of the model with the perforated plate, was higher for all flow rates tested. The accuracy of these simulation results was verified through experiments with Arizona Test Dust. In addition, to simulate the actual operational conditions of the mist eliminator in thermal power plants, limestone slurry particles were used to qualitatively compare the collection performance of mist eliminators. As a result, smaller and fewer limestone slurry particles exited the mist eliminator in the model with the perforated plate in comparison to the reference model. This study showed that mist eliminators actually used in real thermal power plants could be additionally equipped with perforated plates to increase the collection efficiency of the mist eliminator. A systematic parametric study needs to be conducted to characterize the performance of the suggested mist eliminator design using non-dimensional numbers. The mist eliminator model with the perforated plate proposed in this study can be applied in a simple manner to the existing wave-plate mist eliminator, and is expected to contribute greatly to the reduction of particulate matter emitted from various thermal power plants or industrial facilities. Additionally, for the mist eliminator of a shape other than wave-plate, future study is needed to improve dust collection efficiency through simple shape deformation.

\section{ACKNOWLEDGMENT}

This research was supported by the Ministry of Environment as part of the "Korea Environmental Industry \& Technology Institute (KEITI) (No. 2018000120004).

\section{REFERENCES}

Al-Dughaither, A.S., Ibrahim, A.A. and Al-Masry, W.A. (2010). Investigating droplet separation efficiency in wire-mesh mist eliminators in bubble column. J. Saudi Chem. Soc. 14: 331-339. https://doi.org/10.1016/j.jscs.20 10.04.001

ANSYS FLUENT Users Guide 15.0. (2013). Modeling Discrete Phase. FLUENT, Inc., Lebanon, NH, Chap. 24.

Basu, R., Harris, M., Sie, L., Malig, B., Broadwin, R. and Green, R. (2014). Effects of fine particulate matter and its constituents on low birth weight among full-term infants in California. Environ. Res. 128: 42-51. https://doi.org/1 0.1016/j.envres.2013.10.008
Bell, C.G. and Strauss, W. (1973). Effectiveness of vertical mist eliminators in a cross flow scrubber. J. Air Pollut. Control Assoc. 23: 967-969. https://doi.org/10.1080/000 22470.1973.10469867

Brunazzi, E. and Paglianti, A. (1998). Design of wire mesh mist eliminators. AIChE J. 44: 505-512. https://doi.org/1 0.1002/aic.690440302

Brunazzi, E., Paglianti, A. and Talamelli, A. (2003). Simplified design of axial-flow cyclone mist eliminators. AIChE J. 49: 41-51. https://doi.org/10.1002/aic.690490106

Chandranegara, A.S. (2016). Review: Improving mist eliminator performance in gas-liquid separators. Unpublished. https://doi.org/10.13140/RG.2.1.3342.4885

Din, S.A.M., Yahya, N.N.H.N. and Abdullah, A. (2013). Fine particulates matter $\left(\mathrm{PM}_{2.5}\right)$ from coal-fired power plant in Manjung and its health impacts. Procedia Soc. Behav. Sci. 85: 92-99. https://doi.org/10.1016/j.sbspro.2 013.08.341

Dries, H.W. and Hoffmann, A.C. (2019). A correlation giving improved description of the capacity and efficiency of vane-type gas-liquid separators. AIChE J. 65: e16566. https://doi.org/10.1002/aic.16566

Estakhrsar, M.H.H. and Rafee, R. (2013). Effect of drainage channel dimensions on the performance of wave-plate mist eliminators. Korean J. Chem. Eng. 30: 1301-1311. https://doi.org/10.1007/s11814-013-0032-9

Fletcher, RA. and Bright, D.S. (2000). Shape factors of ISO 12103-A3 (medium test dust). Filtr. Sep. 37: 48-56. https://doi.org/10.1016/S0015-1882(00)80200-1

Galletti, C., Brunazzi, E. and Tognotti, L. (2008). A numerical model for gas flow and droplet motion in waveplate mist eliminators with drainage channels. Chem. Eng. Sci. 63: 5639-5652. https://doi.org/10.1016/j.ces.2008.0 8.013

Goodarzi, F. (2006). Morphology and chemistry of fine particles emitted from a Canadian coal-fired power plant. Fuel 85: 273-280. https://doi.org/10.1016/j.fuel.2005.07. 004

Guaita, R., Pichiule, M., Maté, T., Linares, C. and Díaz, J. (2011). Short-term impact of particulate matter $\left(\mathrm{PM}_{2.5}\right)$ on respiratory mortality in Madrid. Int. J. Environ. Health Res. 21: 260-274. https://doi.org/10.1080/09603123.201 0.544033

James, P.W., Wang, Y., Azzopardi, B.J. and Hughes, J.P. (2003). The role of drainage channels in the performance of wave-plate mist eliminators. Chem. Eng. Res. Des. 81: 639-648. https://doi.org/10.1205/026387603322150499

James, P.W., Azzopardi, B.J., Wang, Y. and Hughes, J.P. (2005). A model for liquid film flow and separation in a wave-plate mist eliminator. Chem. Eng. Res. Des. 83: 469-477. https://doi.org/10.1205/cherd.03363

Kang, D. and Kim, J.E. (2014). Fine, ultrafine, and yellow dust: Emerging health problems in Korea. J. Korean Med. Sci. 29: 621-622. https://doi.org/10.3346/jkms.2014.29.5.621

Kavousi, F., Behjat, Y. and Shahhosseini, S. (2013). Optimal design of drainage channel geometry parameters in vane demister liquid-gas separators. Chem. Eng. Res. Des. 91: 1212-1222. https://doi.org/10.1016/j.cherd.2013. 01.012 
Kim, H.J., Kim, J.S., Han, B. and Kim, Y.J. (2019). Mist removal performance of a novel electrostatic precipitation type mist eliminator with a narrow gap at high velocity for coal-fired power plant. 2019 IEEE Industry Applications Society Annual Meeting, Baltimore, MD, USA, pp. 1-9.

Kim, J.H., Mulholland, G.H., Kukuck, S.R. and Pui, D.Y.H. (2005). Slip correction measurements of certified PSL nanoparticles using a nanometer differential mobility analyzer (nano-DMA) for Knudsen number from 0.5 to 83. J. Res. Natl. Inst. Stand. Technol. 110: 31-54. https://doi.org/10.6028/jres.110.005

Kim, T.Y., Kim, H., Yi, S.M., Cheong, J.P. and Heo, J. (2018). Short-term effects of ambient $\mathrm{PM}_{2.5}$ and $\mathrm{PM}_{2.5-10}$ on mortality in major cities of Korea. Aerosol Air Qual. Res. 18: 1853-1862. https://doi.org/10.4209/aaqr.2017.1 1.0490

Lu, H.Y., Wu, Y.L., Mutuku, J.K. and Chang, K.H. (2019). Various sources of $\mathrm{PM}_{2.5}$ and their impact on the air quality in Tainan city, Taiwan. Aerosol Air Qual. Res. 19: 601-619. https://doi.org/10.4209/aaqr.2019.01.0024

Lung, C.C., Chen, S.C., Yang, C.H., Chen, Y.C., Chang, S.Y., Tseng, W.C. and Liu, S.C. (2016). Using atmospheric visibility to assess the effects of air pollution on hospital admissions for respiratory diseases. Aerosol Air Qual. Res. 16: 2237-2244. https://doi.org/10.4209/aaqr.2016.0 3.0111

Manousakas, M., Eleftheriadis, K., and Papaefthymiou, H. (2013). Characterization of $\mathrm{PM}_{10}$ sources and ambient air concentration levels at Megalopolis city (southern Greece) located in the vicinity of lignite-fired plants. Aerosol Air Qual. Res. 13: 804-817. https://doi.org/10.42 09/aaqr.2012.09.0239

Narimani, E. and Shahhoseini, S. (2011). Optimization of vane mist eliminators. Appl. Therm. Eng. 31: 188-193. https://doi.org/10.1016/j.applthermaleng.2010.08.031

Perez, L., Tobías, A., Querol, X., Pey, J., Alastuey, A., Díaz, J. and Sunyer, J. (2012). Saharan dust, particulate matter and cause-specific mortality: A case-crossover study in Barcelona (Spain). Environ. Int. 48: 150-155. https://doi.org/10.1016/j.envint.2012.07.001

Peters, T.M., Ott, D. and O’Shaughnessy, P.T. (2006). Comparison of the Grimm 1.108 and 1.109 portable aerosol spectrometer to the TSI 3321 aerodynamic particle sizer for dry particles. Ann. Occup. Hyg. 50: 843850. https://doi.org/10.1093/annhyg/mel067

Pope, III, C.A., Burnett, R.T., Thun, M.J., Calle, E.E., Krewski, D., Ito, K. and Thurston, G.D. (2002). Lung cancer, cardiopulmonary mortality, and long-term exposure to fine particulate air pollution. J. Am. Med. Assoc. 287: 1132-1141. https://doi.org/10.1001/jama.287.9.1132

Rafee, R., Rahimzadeh, H. and Ahmadi, G. (2010). Numerical simulations of airflow and droplet transport in a wave-plate mist eliminator. Chem. Eng. Res. Des. 88: 1393-1404. https://doi.org/10.1016/j.cherd.2010.03.001

Zamora, B. and Kaiser, A.S. (2011). Comparative efficiency evaluations of four types of cooling tower drift eliminator, by numerical investigation. Chem. Eng. Sci. 66: 12321245. https://doi.org/10.1016/j.ces.2010.12.023

Zhang, C., Yao, Q. and Sun, J. (2005). Characteristics of particulate matter from emissions of four typical coalfired power plants in China. Fuel Process. Technol. 86: 757-768. https://doi.org/10.1016/j.fuproc.2004.08.006

Received for review, May 3, 2020 Revised, July 24, 2020 Accepted, September 12, 2020 